\title{
AULAS DE PORTUGUÊS FORA DA ESCOLA: FAMÍLIAS IMIGRANTES BRASILEIRAS, ESFORÇOS DE PRESERVAÇÃO DA LÍNGUA MATERNA*
}

\author{
Kátia Santos Mota**
}

\begin{abstract}
RESUMO: Este trabalho etnográfico descreve a socialização de 12 famílias brasileiras residentes nos Estados Unidos diante de uma nova língua/ cultura. Foi investigada a competência comunicativa nas duas línguas em cinco domínios sociais. Verificou-se, em crianças/adolescentes, a manifestação do "bilingüismo subtrativo". Formas de ação exercidas pelos pais são reveladas como esforços para assegurar a preservação da língua materna; a igreja e a televisão brasileira demonstram exercer papel relevante no sentido de promover "aulas de conversação" em português.
\end{abstract}

Palavras-chave: Imigrantes brasileiros. Bilingüismo. Preservação da língua materna.

\section{BRAZILIAN IMMIGRANTS:}

EFFORTS FOR FIRST LANGUAGE MAINTENANCE

ABSTRACT: This ethnographic study, involving twelve Brazilian families in the United States, describes the socialization process o people confronted to a new language/culture. The bilingual communicative competence was investigated within five social domains. Children/adolescents of the study manifest a kind of "subtractive bilingualism". Parents express strategies of actions aimed at maintaining the first language. The church community and Brazilian television programs have become important forces to promote "conversational lessons" in Portuguese.

Key words: Immigrants. Bilingual competence. Socialization process.

* Texto revisto e ampliado da comunicação do mesmo título apresentada na XIX Jornada Nacional de Estudos Lingüísticos (Grupo de Estudos Lingüísticos do Nordeste - GELNE), em Fortaleza, setembro/2002.

** Professora da Pós-Graduação em "Educação e Contemporaneidade", da Universidade do Estado da Bahia (UNEB); doutora em Letras pela Brown University; pesquisadora em Interculturalidade e Educação Lingüística.E-mail: motakatia@hotmail.com

Disponível em <http://www.cedes.unicamp.br> 
Aulas de português fora da escola: famílias imigrantes brasileiras...

7 o desenvolver uma pesquisa etnográfica ${ }^{1}$ envolvendo 12 famílias de imigrantes brasileiros residentes nos Estados Unidos, escolhi como foco de atenção a manifestação do processo de aculturação marcado pelo comportamento lingüístico, ressaltando a forma como a convivência entre duas línguas se torna um indicador de afirmação de identidades. Interessava-me, sobretudo, registrar as ocorrências de situações de competitividade ou coexistência lingüísticas em que os atores se defrontam com o desafio de conciliar seu perfil de identidade trazido do país de origem com um outro, que vai se configurando, aos poucos, no país hospedeiro. Neste sentido, a inclusão das duas línguas ou a exclusão de uma delas revela uma tendência de afiliação a um padrão de identidade bicultural ou monocultural que se desenvolve a partir da dinâmica de socialização que acompanha o cotidiano da família.

Ter optado pelo grupo familiar, como informantes da pesquisa, foi um fator decisivo para possibilitar a apresentação de um quadro comparativo entre duas gerações. Este trabalho registra a presença de um forte desejo de conciliação de identidades culturais, com a preservação do bilingüismo, ao mesmo tempo que assinala o papel de destaque que a família, a igreja e a televisão vêm assumindo como espaços informais de aprendizagem. Ao procurar registrar os esforços da família no sentido de preservar a língua materna, quero chamar a atenção para os custos acarretados pela perda lingüística, os quais são altamente significativos, não só no distanciamento da afiliação da sua identidade de origem, mas também como forte fator de desintegração familiar. Considerando que grande parte dos estudos etnográficos se concentra em memórias de histórias familiares resgatadas por um ou outro membro da família, acredito que, como pesquisadora, fui privilegiada em poder trabalhar, por meio de um recorte sincrônico, com um grupo imigrante recém-chegado ${ }^{2}$ aos Estados Unidos. Tal fato favoreceu amplamente uma melhor compreensão das questōes de subjetividade percebidas nas narrativas coletadas, considerando que os atores estão se referindo a experiências vivenciadas no momento presente.

Fishman (1972) chama atenção para o fato de que a língua materna terá mais chance de sobreviver em uma situação de complementaridade lingüística, se houver a preservação do uso funcional de cada uma das línguas dentro de determinados domínios sociais, estimulando a sustentação do bilingüismo estável. Seguindo essa compreensão, nesta pesquisa foram investigados cinco domínios sociais (casa, traba- 
lho, escola, igreja, lazer), na tentativa de se identificar aqueles que mais favorecem a manutenção do português. Os resultados revelaram que: a) o trabalho e a escola apresentam um forte impacto direcionado à assimilação do universo norte-americano, reforçando o bilingüismo subtrativo; ${ }^{3}$ b) nos momentos de lazer, as relaçôes de amizade representam claramente a fronteira lingüística entre as duas geraçōes (nas rodas de amigos, os pais utilizam exclusivamente o português ao passo que os filhos, gradativamente, vão adotando exclusivamente o inglês); c) os principais redutos de preservação da língua materna configuramse nos espaços da casa e da igreja. Optando por enfocar esse último item, pretendo, neste texto, discutir cinco breves tópicos: o perfil representativo dessas famílias como imigrantes brasileiros; a ação escolar no sentido de estimular a assimilação do inglês (mesmo oferecendo programas de educação bilíngüe); as estratégias e os esforços da família no sentido de impor o português como língua dominante na comunicação familiar; as atividades culturais da comunidade que favorecem o uso do português (destacando a televisão); a participação da igreja como o centro comunitário em que a identidade brasileira, em fala portuguesa, é mais fortemente vivenciada em coletividade.

\section{Vivendo entre o Brasil e os Estados Unidos}

Fugindo de dificuldades financeiras resultantes da instabilidade da política econômica no Brasil a partir da década de 1980, os imigrantes brasileiros dizem estar vivendo temporariamente em terra estrangeira na intenção de fazer dinheiro para retornar ao país. Estabelece-se, assim, uma situação de vida dividida entre duas realidades: estar nos Estados Unidos para organizar a vida no Brasil. As pesquisas revelam, entretanto, um descompasso entre a intenção expressa pelo grupo e a realidade que vão construindo fora do Brasil. Mesmo elaborando o retorno, eles vão prolongando sua permanência nos Estados Unidos, configurando-se, assim, uma situação de inbetweeness, de viver entre dois mundos (Margolis, 1994; Reis \& Sales, 1999).

$\mathrm{O}$ desejo de permanência ou de transitoriedade da imigração manifesta-se, pelos relatos coletados, em três subgrupos com diferentes razões que justificam a preservação da interculturalidade com inclusão das duas línguas: (a) sete famílias expressam a decisão de ficar nos Estados Unidos, acreditando que algum dia vão se tornar cidadãos norte-ameri- 
Aulas de português fora da escola: famílias imigrantes brasileiras...

canas, mas acrescentam que, para manter o bem-estar da família, é importante que o Brasil continue vivo na tradição familiar; (b) quatro famílias afirmam estar se preparando para voltar ao Brasil, acreditando que a permanência nos Estados Unidos vale não só como investimento financeiro mas também como capital cultural, pois assegura-lhes melhores condições de trabalho no retorno ao Brasil; (c) apenas uma família diz viver em um constante estado de indecisão, oscilando entre as vantagens e desvantagens de ficar ou de retornar ao Brasil.

Independentemente de qual seja o projeto familiar, observa-se que os pais, em geral, mesmo seguindo diferentes motivaçôes, são perfeitamente conscientes do papel que a língua materna desempenha. No primeiro subgrupo, o português torna-se importante como elemento de marcação da tradição brasileira; no segundo, apesar da função instrumental que o inglês assume como investimento financeiro/cultural, há uma grande preocupação em não perder o português para evitar que, no retorno ao Brasil, os filhos sejam rebaixados na série escolar; no terceiro, o esforço é dobrado, pois na perspectiva de não ter clareza quanto ao país que deve ser referência de residência, percebe-se que a perda de qualquer uma das línguas serve como ameaça de impossibilidade para a escolha do país onde se fixar. Foi observado, entretanto, que a evolução lingüística, nas duas gerações, seguem caminhos divergentes. Os pais demonstram uma grande dificuldade no processo de aquisição da segunda língua; o inglês constitui-se uma barreira quase intransponível para o imigrante adulto. $\mathrm{O}$ mal-estar generalizado, o choque cultural e a sensação de exclusão/ não-pertencimento vão se acumulando, provocando no indivíduo um sentimento de impossibilidade de inserção na sociedade norte-americana. Os filhos, em contrapartida, seguem um ritmo bem acelerado na evolução da competência comunicativa em inglês e no desempenho do português, entretanto, com o passar do tempo, conseguem manter com mais facilidade as habilidades receptivas (ouvir e ler), mas gradualmente vão perdendo as habilidades expressivas (falar e escrever). Um dado altamente relevante é que o processo de perda da língua materna nos filhos segue um ritmo bem mais acelerado do que o de aquisição da segunda língua nos pais.

Estabelecem-se, assim, situações de conflitos lingüísticos que dificultam a dinâmica social da família; a competitividade entre as geraçôes acentua-se, causando inversão nas relaçôes de poder. 
Parece que, quando vão conversar, as palavras delas saem melhor no inglês. Eu não gosto, não. Eu digo para elas: Faça favor, falem em português. E elas me respondem: Mãe, é bom para você também, pra você aprender. Mas eu digo: Eu não quero, eu prefiro não aprender, mas não quero que vocês percam o português. Acho que, se eu aprender inglês, elas acabam esquecendo o português. Eu não quero isso. (Mãe, família Pereira)

Dessa forma, as fronteiras lingüísticas promovem o distanciamento entre pais e filhos, atribuindo à língua a função de retenção e manipulação de autoridade, manifestada por meio de estratégias conversacionais que definem a inclusão ou exclusão de identidades dentro do contexto familiar. O diálogo entre pais e filhos é impossibilitado não só pelos diferentes códigos lingüísticos, mas também pela conscientização de que a competência comunicativa na língua de maior prestígio gera um domínio nas relações de poder ancoradas na linguagem.

Quase sempre eu brigo com meu filho quando ele começa a falar inglês. Eu digo: Filho, eu não estou entendendo o que você está falando. Você tem que falar português para mim. Tinha vez que ele me dizia: $A h$, mãe, a senhora é muito burra. A senhora não quer aprender. Então, a gente encontra dificuldade para conversar. (Mãe, família Santana)

Nas relações familiares, os filhos ganham ainda maior poder quando passam a assumir funções primordiais à sobrevivência dos pais, tais como a de porta-voz, tradutor e intérprete, principalmente em transações ocorridas em agências de serviços públicos. Muitas vezes quer se afirmar a "normalidade" do fato, mas sempre se deixa passar uma sensação de desconforto nos seus relatos.

No princípio me sentia ridícula, mas agora já acho isso normal na vida diária. Até já peço para minha filha falar por mim. No princípio eu me sentia assim: Como é que pode minha filha estar falando por mim? Me sentia assim como se faltasse um órgão em meu corpo por não saber me comunicar. Mas você muda. Não estou me preocupando mais se não falo inglês. Eu antes vivia deprimida. Não consigo falar o que quero. Não consigo dialogar. (Mãe, família Souza)

Outros dados interessantes no círculo familiar também foram registrados com referência à comunicação entre irmãos, apresentando três padróes de ocorrência: os filhos únicos ou os mais velhos têm 
Aulas de português fora da escola: famílias imigrantes brasileiras...

mais chances de se tornarem bilíngües porque conseguem manter mais naturalmente a comunicação com os pais em português; os filhos mais novos, em contrapartida, normalmente se comunicam com os irmãos mais velhos em inglês e, muitas vezes, comunicam-se com os pais utilizando os irmãos mais velhos como intérpretes; as meninas, na sua maioria, são mais motivadas a manter a língua materna, pois apresentam um grau maior de solidariedade com os pais e de preocupação com a possibilidade de retorno ao Brasil (mantêm-se mais informadas sobre o Brasil e correspondem-se com mais freqüência com amigos no Brasil).

A tendência geral, entretanto, é de que as geraçôes mais jovens adotem o inglês como língua dominante e, assim, vá se cristalizando uma barreira mais duradoura no processo de socialização familiar: perde-se não só a língua materna como veículo de comunicação, mas quebra-se também o direito paterno/materno de exercer a autoridade familiar, de passar a tradição étnica, suas histórias, valores e sentimentos. Em médio prazo, serão manifestados efeitos negativos no desenvolvimento social, cognitivo e emocional dessas crianças e adolescentes, ao mesmo tempo em que é afetada a integridade da família, com possíveis repercussões de desajustes sociais (Fillmore, 1991).

\section{Onde fica (não fica) o português no espaço escolar}

Somerville foi escolhida como local da pesquisa em razão do índice crescente de matrículas de crianças brasileiras na rede pública de ensino, principalmente nos programas de educação bilíngüe. ${ }^{4}$ Os programas bilíngües inglês-português são oferecidos nos três primeiros anos de escolaridade, assim distribuídos: no primeiro ano, o aluno tem $75 \%$ das atividades em português; no segundo, $50 \%$ das atividades são conduzidos em cada uma das duas línguas; e no terceiro ano, $75 \%$ das atividades são em inglês e os $25 \%$ restantes, em português. Esse modelo pedagógico é considerado transicional porque se espera que, a partir do quarto ano, o aluno passe a freqüentar as classes regulares; nessa ideologia educacional, o ensino-aprendizagem em língua materna serve como ponte para se alcançar a segunda língua. $\mathrm{Na}$ verdade, a meta educacional, sem dúvida, é a assimilação lingüística em que, no longo prazo, a perda da língua materna parece ser inevitável. Os estudos mostram que tais programas não conseguem 
desenvolver uma situação de bilingüismo estável, nem muito menos estimular a formação de uma identidade bicultural (Skutnabb-Kangas \& Cummins, 1988).

Ao participar durante dois semestres das reuniōes do Círculo de Pais Imigrantes e acompanhar, por meio de visitas, questionários e entrevistas, o processo de socialização das 12 famílias do estudo, consegui registrar depoimentos que revelam um alto nível de frustração dos pais com relação às suas expectativas iniciais sobre os programas de educação bilíngüe: apresentam a constatação de uma prática pedagógica ineficiente com relação aos materiais didáticos e à seleção de professores, assim como ao baixo nível de exigências quanto ao aproveitamento escolar. Fica claro, então, que tais programas 5 funcionam muito mais como uma forma de acolhimento menos traumático de adaptação ao currículo pleno em inglês do que como uma política educacional que pretenda contribuir para a manutenção da tradição étnica dos alunos.

\section{Querer que a casa se torne escola parece não dar certo}

Eleger o português, de forma consistente, como língua primordial no espaço da casa parece ser a maneira mais eficiente de contribuir para o desenvolvimento da competência comunicativa na língua materna: se os pais mantêm perseverança em se expressar sempre em português, os filhos vão naturalmente adotando essa língua na comunicação intrafamiliar (Saunders, 1988). Essa postura é perfeitamente visível como meta determinada pelas famílias investigadas. A imposição do uso do português em casa atende, na verdade, a duas necessidades expressas pelos pais: a primeira refere-se ao desejo de assegurar a manutenção da identidade brasileira, de manter o vínculo com a terra de origem, deixando aberta a possibilidade de retorno; a segunda manifesta a garantia de preservar a autoridade paterna/materna na dinâmica das relaçôes interpessoais no contexto familiar. Neste sentido, é por meio do uso do português que os pais vinculam a escolha lingüística à necessidade de pertencimento a uma identidade nacional e, em contrapartida, mantêm a estabilidade na hierarquia de poder entre geraçôes. Em alguns relatos, percebe-se claramente a crença de que, ao deixar que o inglês assuma o espaço da casa, não somente os filhos vão perder o domínio da língua materna, mas os pais "per- 
Aulas de português fora da escola: famílias imigrantes brasileiras...

derão" seus filhos, não apenas na forma de autoridade sobre eles mas também na troca de discursos de intimidade.

Eu comecei a me assustar quando vi que minha filha já estava falando bem inglês com as coleguinhas e eu não entendia nada. Eu vi que estava perdendo o domínio da casa. Como é que vai ser? Amanhã ela vai saber tudo e eu não vou saber nada? (Mãe, família Rocha)

Em muitas situações foram, entretanto, observados comportamentos lingüísticos que deflagram certas inconsistências entre o que se acredita e o que se manifesta na comunicação espontânea. Assim, durante as observações, foram registrados momentos em que os pais conversam com os filhos utilizando palavras ou mesmo sentenças em inglês, na tentativa de afirmar o seu processo de evolução lingüística, de demonstrar o seu saber, a sua capacidade de aprender. Quase sempre, entretanto, expõem-se às críticas ou correções dos filhos, contribuindo para reforçar ainda mais as suas inseguranças e os conflitos psicológicos. Algumas vezes, os próprios filhos dizem que preferem falar inglês em casa para ajudar os pais a aprenderem melhor o inglês; neste sentido, expressam preocupação, ou até mesmo vergonha, diante da incompetência dos pais em falarem a língua estrangeira.

Muitos jovens, mesmo acreditando na importância de preservar a língua materna, expressam discordância da atitude de imposição exercida pelos pais. As constantes reivindicações no sentido de falar português tornam-se, na visão dos filhos, abusivas, provocando, muitas vezes, uma ausência de diálogo entre pais e filhos ou um cenário bipartido em dois mundos lingüísticos: os pais conversando entre si em português e os filhos, em inglês. Esses dois círculos de conversação vão se distanciando, sugerindo que, em futuro breve, as fronteiras lingüísticas podem vir a ameaçar a unidade familiar. Essa possibilidade se configura em uma sensação de medo constantemente presente no discurso dos pais. A reação manifesta-se quase sempre em atitudes de reforço à imposição do uso do português e de vigilância à correção lingüística. Essas duas estratégias (a imposição lingüística e a excessiva correção do português dos filhos) podem, na verdade, segundo Saunders (1988), ter um efeito contrário, atuando muito mais fortemente na perda lingüística do que na manutenção. Foram vários os registros em que as crianças/adolescentes tentavam manter naturalmente uma conversa em português e a mãe, repetidas vezes, 
chamava a atenção para os erros gramaticais. Neste sentido, quase sempre as conversas eram subitamente interrompidas ou alternadas para o inglês.

- Eu não conheço muito música brasileira, eu só ouvo.

- Ouço e não ouvo. Juliana, repita direito.

- Eu ouve muito as músicas.

- Ouço, Juliana. O-U-Ç-O (escrevendo)

- Ouço (diminuindo o tom de voz e silenciando-se meio envergonhada). (Juliana Silva, 10 anos, e sua mãe)

Percebe-se, assim, que os pais, não acreditando simplesmente que o uso espontâneo do português em casa possa assegurar a preservação da língua, passam a assumir o papel de professores de português dos filhos. Torna-se necessário, então, criar uma dinâmica de sala de aula dentro de casa. Em algumas famílias são estabelecidos horários regulares para o estudo sistemático da língua portuguesa por meio de livros didáticos brasileiros, na tentativa de manter um currículo paralelo coerente com o sistema escolar no Brasil. Além disso, o período de férias escolares muitas vezes transforma-se em "curso intensivo" de português. Acreditam que "instalar uma escola brasileira" em casa seja a única forma de fazer com que os filhos mantenham "o respeito à língua portuguesa”.

- Eles estão conseguindo manter o português porque é uma exigência nossa. A tendência deles é conversar em inglês. A gente é que fica lembrando: "Português, português, português". Até quando os amigos brasileiros vão lá em casa eles falam em inglês. Aí, eu digo: "Aqui em casa ninguém entende inglês. Tratem de falar em português". Aí eles falam duas ou três palavras em português e voltam para o inglês. Não é fácil. (Mãe, família Silva)

Aprende-se português (de forma mais eficiente) nos espaços de interação comunitária

Sem deixar de reconhecer as intenções positivas dos pais ao estabelecerem tarefas escolares, ficou evidente que as famílias que demonstram uma interação mais saudável em português não são necessariamente aquelas que transformam a casa em ambiente escolar. A manutenção do português fica muito mais assegurada quando os pais desenvolvem atitudes mais naturais de convivência com a língua materna e com a cultura brasileira; o exemplo de demonstração de ser 
Aulas de português fora da escola: famílias imigrantes brasileiras...

brasileiro reservando espaços do cotidiano vinculados a elementos da cultura brasileira traz efeitos muito mais significativos para a preservação do português. A presença na casa de símbolos culturais relacionados à vida brasileira (objetos típicos do Brasil, a bandeira nacional na parede, produtos culinários etc.) demonstra uma representação da identidade nacional que atua como elemento motivador da comunicação em português. A marcação do espaço brasileiro sugere o falar em português, sem imposição explícita; ao oferecer um guaraná brasileiro, por exemplo, naturalmente se inicia a conversa em português. São recursos de sensibilização cultural que mais eficientemente seduzem os jovens a querer buscar vínculos com sua origem. Nos encontros comunitários, principalmente nas festividades comemorativas tipicamente brasileiras (como o carnaval e o futebol), mesmo aqueles mais jovens, que já demonstravam maior fluência no inglês, procuravam usar o português como forma de se inserir no grupo, de se sentir mais engajados. Certamente era nesses momentos que ocorriam as melhores oportunidades de aprendizagem para a revitalização do português. Vale destacar também que a música brasileira exerce um grande fascínio sobre crianças e jovens; fiquei bastante surpresa ao ver o alto nível de interesse em saber as letras das músicas, não só aquelas mais em evidência como também as mais antigas, que fazem parte do repertório dos pais.

Mais forte do que a música, entretanto, é a influência da televisão brasileira nas horas de lazer das famílias. Tanto os pais como os filhos acreditam que a televisão brasileira é bem melhor que a americana; é comum, durante os fins de semana, passarem horas assistindo a vídeos dos programas semanais. ${ }^{6}$ Os mais assistidos, por ordem de preferência, são: as novelas da Globo, Fantástico, Globo Repórter, Jornal Nacional, Globo Rural, Video Show e Sílvio Santos. Os adolescentes dizem aprender muito com as novelas: o jeito de viver no Brasil, as praias, as festas, a moda; ressaltam, entretanto, que sabem que nada é verdadeiro porque "é tudo um país de mentira". Interessante é que, em alguns relatos de aprendizagem, esses adolescentes reconhecem que a televisão também está ensinando a língua portuguesa.

- Gosto demais de ver novela brasileira. Já vimos tudo que é novela. Quando a gente pega a fita, a gente termina querendo ver a fita todinha. Acho que é um vício. Não é só as meninas, não. Os meninos também gostam. A gente 
aprendeu a dizer "isso é coisa de frutinha" em Malhação. No verão passado todo mundo dizia: "Isso é coisa de frutinha". A gente aprende principalmente gíria. Adoro novela. (Carol Pereira, 15 anos)

Confrontando a participação dos pais no sentido de estabelecer duas diferentes estratégias de ensino-aprendizagem de português - ou dando formalmente aulas de português em casa ou promovendo um espaço de interação social em língua portuguesa -, o quadro seguinte identifica atitudes positivas e negativas que, direta ou indiretamente, contribuem ou não para a preservação lingüística.

\begin{tabular}{|c|c|}
\hline $\begin{array}{l}\text { Atitudes positivas à preservação } \\
\text { da língua portuguesa: }\end{array}$ & $\begin{array}{c}\text { Atitudes negativas à preservação } \\
\text { da língua portuguesa: }\end{array}$ \\
\hline $\begin{array}{l}\text { - persistência em utilizar português em } \\
\text { casa de forma espontânea; } \\
\text { - participação efetiva na comunidade } \\
\text { brasileira; } \\
\text { - preservação dos laços familiares com } \\
\text { parentes no Brasil (visitas, trocas de } \\
\text { fotos, presentes, e-mails, telefonemas); } \\
\text { - inserção de elementos da cultura bra- } \\
\text { sileira no ambiente da casa (quadros, } \\
\text { músicas, comidas, fotos); } \\
\text { acompanhamento da vida social brasi- } \\
\text { leira por intermédio de TV, revistas e } \\
\text { jornais. }\end{array}$ & $\begin{array}{l}\text { - expressão de insatisfação generalizada } \\
\text { com as coisas do Brasil; } \\
\text { rejeição ao convívio com a comunida- } \\
\text { de brasileira; } \\
\text { - preocupação demasiada com o futuro } \\
\text { profissional dos filhos nos Estados } \\
\text { Unidos; } \\
\text { - } \text { autoritarismo ao impor o uso do por- } \\
\text { tuguês em casa (estudo forçado da lín- } \\
\text { gua e excesso de correções); } \\
\text { recriminação constante ao uso do in- } \\
\text { glês em casa e às manifestações cultu- } \\
\text { rais norte-americanas; } \\
\text { críticas reforçando a ignorância dos fi- } \\
\text { lhos com relação à cultura brasileira; } \\
\text { constantes comparaçôes com a vida es- } \\
\text { colar dos primos no Brasil, manifes- } \\
\text { tando incerteza quanto ao aproveita- } \\
\text { mento escolar dos filhos. }\end{array}$ \\
\hline
\end{tabular}

Na igreja, o "correto" é falar português

Ao conversar com um menino de 7 anos, que durante toda a entrevista insistia em responder em inglês às perguntas feitas em português, notei que, ao falar sobre a igreja, ele trocou imediatamente 
Aulas de português fora da escola: famílias imigrantes brasileiras...

para o português. Diante do meu estranhamento, explicou-me: “... rezar? só em português". Essa foi mais uma constatação de que a igreja, identificada na pesquisa como o domínio social cuja escolha lingüística se apresenta claramente definida como "exclusivamente português", constitui-se o reduto de maior preservação da língua materna, onde a tradição étnica se manifesta como simbolização do espírito de solidariedade do grupo. ${ }^{7}$ Tanto os pais como os filhos afirmam categoricamente: "Lá na igreja todo mundo tem que ser brasileiro".

A participação efetiva nas atividades da igreja (oito famílias manifestaram uma forte afiliação) proporciona oportunidade de socialização com outras famílias, mas também as manifestações de fé religiosa exercem um forte papel no sentido de amenizar as tensôes emocionais de se viver clandestinamente em um país estrangeiro. São muitos os brasileiros que não costumavam freqüentar a igreja no Brasil e que se tornam, nos Estados Unidos, membros ativos por razóes espirituais, emocionais, sociais, mas também porque as igrejas (católica e protestante) funcionam como rede de apoio, prestando serviços sociais de extrema importância, que facilitam a vida do imigrante.

Grande parte da vida social das crianças e dos adolescentes também se passa na igreja: muitos freqüentam a escola dominical ou os grupos de catequese. Todas essas atividades, inclusive as cerimônias religiosas, são exclusivamente em português; a igreja torna-se, então, o mais eficiente espaço informal de ensino-aprendizagem da língua portuguesa. Foram registradas várias situações de "sala de aula" bem interessantes como, por exemplo, o caso de uma adolescente de 15 anos que dá aula de catequese para crianças pequenas e que oferece chocolate como prêmio para aqueles que conseguirem não falar nenhuma palavra em inglês durante a aula. Em uma outra ocasião observei o caderno de religião de duas irmãs de 7 e 9 anos que me apresentavam como sendo também o caderno de português; faziam parte de uma família de testemunhas de Jeová e as meninas tinham aulas de estudos bíblicos duas vezes por semana, além do culto nos domingos. A mãe reconhece que é principalmente na igreja que as meninas "estudam português" porque são obrigadas semanalmente a ler textos bíblicos e fazer resumos destes no caderno.

Percebemos que a igreja apresenta duas fortes estratégias no sentido de preservar a língua materna: a primeira, de forma espontânea, 
pela participação nos cerimoniais religiosos e nos eventos sociais em geral, os quais, como práticas de interação social, promovem o desenvolvimento da competência comunicativa em português; a segunda, de forma mais sistematizada, por meio de aulas, encontros de grupos e palestras, pelos quais se estimula a oralidade em português assim como atividades de leitura e escrita.

\section{Notas conclusivas}

Considerando que a casa se configura em dois espaços de aprendizagem: quando assume a função escolar e os pais se tornam professores/fiscalizadores do desempenho lingüístico dos filhos ou quando promovem vínculos interativos com a língua/cultura brasileira, fica evidente que, na segunda estratégia, ela se torna muito mais eficiente que na primeira. Destaco, entretanto, os papéis altamente relevantes da televisão e da igreja, as quais, ao assumirem um espaço significativo da vida cotidiana, oferecem as mais eficientes "aulas de português". Segundo as teorias de aquisiçãao da segunda língua, são espaços como esses que se tornam primordiais porque oferecem condiçōes favoráveis para "aquisição lingüística com baixo nível de interferência emocional” (Krashen, 1981). Seguindo também o modelo sociointeracionista da evolução da linguagem, são as relações interpessoais emolduradas nas trocas discursivas que garantem a internalização dos padrôes gramaticais de uma determinada língua (Vygotsky, 1962).

Em síntese, não sabemos quais as chances reais que essas crianças e adolescentes têm de preservar a língua materna e alcançar um padrão adequado de bilingüismo estável. Sabemos que há uma grande força social no sentido de acelerar o processo de assimilação do inglês, mas também identificamos muitas famílias que, desejosas de reconstruir uma comunidade brasileira em terra estrangeira, vêm exercendo esforços no sentido de assegurar a preservação da língua e da cultura brasileira. É exatamente esse fortalecimento da comunidade que atua como o elemento mais poderoso para que a língua portuguesa seja mantida viva no universo social das crianças e dos jovens.

Recebido em agosto de 2003 e aprovado em abril de 2004. 
Aulas de português fora da escola: famílias imigrantes brasileiras...

\section{Notas}

1. Pesquisa realizada como trabalho de campo da tese de doutorado intitulada Imigrantes brasileiros nos Estados Unidos: trajetórias de identidades em uma situação de bilingüismo, Brown Universtity, 1999.

2. A pesquisa envolveu 12 famílias totalizando 22 adultos e 24 crianças e adolescentes, com tempo de residência em Somerville, Massachusetts, variando de 3 a 10 anos.

3. O conceito "bilingüismo subtrativo" foi desenvolvido por Lambert (1972), em oposição à situação de "bilingüismo aditivo", em que as duas línguas convivem harmonicamente.

4. Nos programas de educação bilíngüe, em 1998/1999, foram registradas 283 crianças/ adolescentes brasileiras de um total de 353 falantes de português.

5. Os programas de educação bilíngüe de manutenção, em contrapartida, são considerados altamente eficientes para o sucesso escolar dos alunos (Skutnabb-Kangas \& Cummins, 1988; Nieto, 1992).

6. Na época da pesquisa as famílias alugavam vídeos dos programas; um ou dois anos depois a TV Globo instala-se como canal pago na TV por cabo. Pressupōe-se, com isso, que o tempo de exposição à língua portuguesa, via TV, deve ter se estendido consideravelmente, facilitando ainda mais a aquisição lingüística.

7. O papel social da Igreja, assumido para os serviços sociais do grupo de imigrantes brasileiros, é amplamente discutido por Martes, em Reis \& Sales (1999, p. 87-122).

\section{Referências bibliográficas}

FILLMORE, L.W. When learning a second language means losing the first. Early Childhood Research Quaterly, n. 6, p. 323-46, 1991.

FISHMAN, J. (Ed.). Language loyalty in the United States. The Hague: Mouton, 1966.

FISHMAN, J. The sociology of language. Rowley: Newbury House, 1972.

KRASHEN, S. Second language acquisition and second language learning. Oxford: Pergamon, 1981.

LAMBERT, W.E. Language, psychology, and culture. Stanford: Stanford University, 1972.

MARGOLIS, M. Little Brazil: an ethnography of Brazilian immigrants in New York City. Princeton, NJ: Princeton University, 1994.

NIETO, S. Affirming diversity: the sociopolitical context of multicultural education. New York: Longman, 1992. 
REIS, R.; SALES, T. (Org.). Cenas do Brasil migrante. São Paulo: Boitempo, 1999.

ROMAINE, S. Bilingualism. Oxford; New York: Blackwell, 1994.

SAUNDERS, G. Bilingual children: from birth to teens. Philadelphia: Multilingual, 1988.

SKUTNABB-KANGAS, T.; CUMMINS, J. (Ed.). Minority education: from shame to struggle. Philadelphia: Multilingual, 1988.

VELTMAN, C. Language shift in the United States. New York: Mouton, 1983.

VYGOTSKY, L.S. Thought and language. Cambridge, Mass.: MIT, 1962. 